This is a self-archived final draft version of the original article. It may differ from the original in pagination and typographic detail.

Cite

Länsiluoto, A., Joensuu-Salo, S., Varamäki, E., Viljamaa, A. \& Sorama, K. 2018. Market orientation and performance measurement system adoption impact on performance in SMEs. Journal of Small Business Management. First published: 5 January 2018.

DOI:10.1111/jsbm.12393

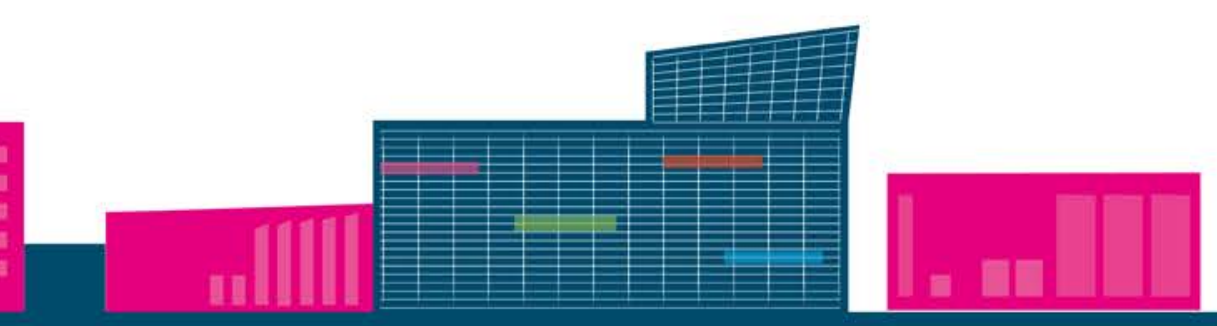


Submitted to Journal of Small Business Management

\title{
Market orientation and performance measurement system adoption impact on performance in SMEs
}

Aapo Länsiluoto ***

Sanna Joensuu-Salo (corresponding author) $* *$

Elina Varamäki **

Anmari Viljamaa **

Kirsti Sorama**

${ }^{* * *}+$ In memoriam: our respected and much missed colleague Dr. Aapo Länsiluoto

** Seinäjoki University of Applied Sciences, P.O. Box 412, FI-60101 Seinäjoki, Finland

\begin{abstract}
Previous research has shown a connection between market orientation (MO) and firm performance, as well as between performance measurement systems (PMS) adoption, but their mutual interactions are as yet little understood in SMEs. Using empirical data collected by a survey from 123 Finnish SMEs we analyze the relationship between MO, PMS adoption and performance. According to the results, MO has positive relationships with PMS adoption and non-financial performance. However, the impact of MO on financial performance is mediated by PMS adoption. PMS adoption is thus an important factor in explaining variance in firm performance. Finally, empirical analysis shows that the larger SME firms adopt PMS more extensively.
\end{abstract}

Keywords: Market orientation, performance measurement systems, firm performance, small firms 


\section{Introduction}

Market orientation (MO) has, since the seminal articles of Narver and Slater (1990) and Kohli and Jaworski (1990), been the object of intense research efforts (e.g. González-Benito et al. 2014; Liao et al. 2011). Overall, previous studies suggest that MO is positively associated with firm performance (e.g. Kirca, Jayachandran and Bearden, 2005), and some studies even suggest that it is becoming a necessity rather than a source of competitive advantage for firms (Kumar et al. 2011). From a cultural perspective MO can be viewed as a part of organizational culture (Narver and Slater, 1990), but from a behavioural perspective it is described as market-driven behaviours (Jaworski and Kohli, 1993). In Kohli and Jaworski's (1990, see also Hult et al. 2005) definition MO consists of three different activities: 1) generation of market intelligence pertaining to current and future customer needs, 2) dissemination of the intelligence across departments, and 3) organizationwide responsiveness to it. Thus, systems for handling information have potentially a key role in MO implementation.

In addition to MO, this study focuses on performance measurement systems (PMS) which have been implemented for information handling. The importance of PMS has been discussed largely in accounting literature (e.g. Franco-Santos et al. 2012; Ittner et al. 2003; Said et al. 2003; and van der Stede et al. 2006). Franco-Santos et al. (2012) define PMS as both financial and non-financial performance measures used to inform decision-making and to evaluate firm performance. Earlier research shows that PMS can improve firm performance in several ways as proposed by FrancoSantos et al. (2012, see also Chapman and Kihn 2009; Garengo et al. 2005; Ittner et al. 2003; Lamberti and Noci 2010; Martin et al. 2009; van der Stede et al. 2006). However, a number of studies have also shown the challenges in PMS use and implementation (Nudurupati et al. 2011), and small and medium-sized enterprises (SMEs) can be considered a particularly challenging context for PMS adoption. According to Garengo et al. (2005, see also Ates et al. 2013), small firms have limited capital and human resources, lack managerial capacity, have a reactive approach, give little attention to formalization of processes and, finally, often fail to see the benefits of PMS.

As noted above, however, MO implies extensive gathering and utilization of information. One might therefore expect even small firms with high MO to have an interest in adopting PMS. The relationship between MO and information produced by PMS is not, however, clear-cut. PMS generally produces information for several different purposes (Franco-Santos et al. 2012), relating to employees, internal processes, learning and growth, stakeholders and financial success (see for instance Kaplan and Norton 2005). Choice of measurement metrics can be influenced by the degree of MO (e.g. Ambler 
et al. 2004) and different stakeholders including customers (Länsiluoto et al. 2013). So far only a few empirical studies have investigated how MO is associated with PMS and firm performance. Existing research has focused on customer (Hyvönen 2007) or marketing-mix performance (Mintz and Currim 2013), or on marketing performance measurement (Homburg et al. 2012, see also O’Sullivan and Abela 2007). We contribute to the findings of these earlier studies (i.e. Homburg et al. 2012; Hyvönen 2007; Mintz and Currim 2013; O’Sullivan and Abela 2007) by considering the overall PMS (and firm performance) rather than only marketing or customer perspectives (and customer performance). The focus on overall PMS is important, because generally PMS are constructed so as to provide information from several perspectives, of which marketing and customers are only a few.

The context of this study is SMEs. A literature review by Raju et al. (2011) reveals numerous studies which have investigated the relationship between MO and firm performance in SMEs. Raju et al. (2011) describe several studies, which have found a direct positive relationship between MO and firm performance (e.g. Baker and Sinkula 2009; Pelham 2000) but also studies which found no relationship at all, or a moderated (i.e. market turbulence) or a mediated (i.e. innovation and quality practices) relationship. The mixed results indicate that there is still a need to examine the relationship between MO and firm performance in the SME context.

All in all, earlier studies do not provide a clear picture on the relationship between MO and PMS adoption and their effect on firm performance in SMEs. Therefore, the specific purpose of this study is to examine in an SME context the association between MO and PMS adoption, and their relationship with firm performance.

\section{Earlier studies and hypothesis development}

MO has been primarily discussed in marketing literature, where previous studies suggest that MO is positively associated with general firm performance (e.g. Kirca et al. 2005), although the relationship between MO and firm performance can be moderated or mediated by different factors (see GonzálezBenito et al. 2014; Hyvönen, 2007; Kirca et al. 2005; Liao et al. 2011). González-Benito et al. (2014) find a positive relationship between market orientation and firm performance, but the relationship is affected by competitive intensity (cf. Homburg et al. 2012). Kirca et al. (2005) find that MO and firm performance are mediated by innovativeness, customer loyalty and quality and moderated by industry type. According to Kirca et al. (2005), manufacturing firms have higher market orientationperformance associations than service firms. Taken together, earlier studies fail to provide a consistent and comprehensive view on the relationship between MO and firm performance. 
One reason for inconsistencies might be that PMS have an effect on the relationship between MO and firm performance. PMS have been a popular research area, but only a few quantitative empirical studies have considered the relationship between PMS and firm performance in the context of marketing and market orientation (Homburg et al. 2012; Hyvönen 2007; Mintz and Currim 2013; O’Sullivan and Abela 2007). A reason for the shortage of empirical studies might be that marketing scholars investigating MO and accounting scholars examining PMS employ different media, and the discussions hence fail to combine. Some exceptions can nevertheless be identified. Homburg et al. (2012) find that marketing alignment and market-based knowledge mediate the relationship between PMS and firm performance, suggesting that only firms with a strategic focus on marketing benefit from PMS. The result is suggestive although their focus is on comprehensiveness of marketing PMS rather than on general PMS.

Hyvönen (2007) on the other hand investigates the effect of performance measure diversity and information technology on the relationship between customer-focused strategy and customer performance, but fails to find empirical support for moderation when two-way interaction is used. Hyvönen (2007) did find a negative three-way interaction relationship between customer performance and customer-focused strategy, performance measure diversity and IT, suggesting that contemporary performance measures do not help firms with highly customer-focused strategies to achieve higher customer performance. This might be due to non-alignment and over-complexity of measures. In another interesting study O’Sullivan and Abela (2007) find that the ability to measure marketing performance has a significant impact on firm profitability and stock returns. In a similar direction points also the study by Mintz and Currim (2013), who find that PMS use (marketing and financial measures in their study) is positively associated with marketing-mix performance (e.g. customer satisfaction, customer loyalty, sales or market share). The results of the aforementioned studies are suggestive, although their design differs somewhat from ours; we focus on general (not only marketing) PMS (cf. Homburg et al. 2012; O’Sullivan and Abela 2007) and use firm performance (i.e. not only customer performance) as a dependent variable (cf. Hyvönen 2007; Mintz and Currim 2013).

The specific context of our study is SMEs. According to Ates et al. (2013, see also Garengo et al. 2005), SMEs have for instance limited resources (that is, human, finance and time resources), poor managerial skills, non-formalized structures to manage performance, reactive approach to management, and both internal and short-term operational focus. This suggests less interest in PMS by SMEs in general (Chenhall 2003). PMS adoption in SMEs may also be hindered by the fact that PMS are usually developed with larger companies in mind (Ates et al. 2013; Taticchi et al. 2010; see 
also Chenhall 2003). Another reason for failure to adopt PMS may be that, due to the smaller size of the firm, deviant events such as customer complaints or process breakdowns are more visible also without formal PMS (Garengo et al. 2005). Also, SMEs managers and owners have personal networks to gather information and thus may view PMS as unnecessary for managerial purposes (Ates et al. 2013). Still, studies have shown that PMS can be helpful in small firms as well, particularly if the firms are highly market oriented. The benefits of PMS are discussed in more detail in connection with hypotheses development.

Figure 1 illustrates our theoretical model. The model proposes that firms with high MO have better firm performance and also have adopted PMS to a higher degree. Marketing literature (e.g. Cano, Carrillate and Jaramillo 2004; Kirca et al. 2005) suggests that MO is an important factor for firm performance, and earlier studies on PMS suggest that PMS can be used to implement (MO) strategy, communicate goals, evaluate the selected strategy and facilitate both learning and improvement (e.g. Lamberti and Noci 2010). Furthermore, our model expects that PMS adoption is associated with firm performance, since PMS can provide critical information from several different perspectives for decision making, helping to improve or maintain good firm performance. Finally, the model suggests that PMS adoption is affected not only by MO but also the size of the firm (see Chenhall 2003). All the relationships are expected to have positive coefficients and are explained in more detail in the next subchapters.

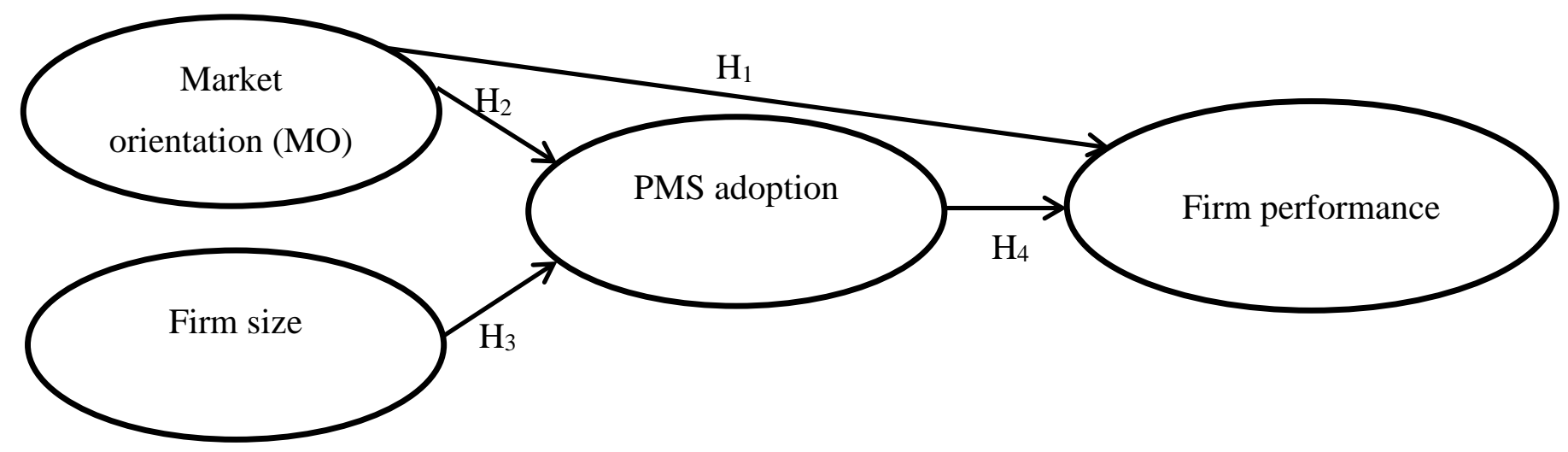

Figure 1. Theoretical model

Market orientation and firm performance

The construct of MO is based on the assumption that firms seek to gain sustainable competitive advantage and long-term profitability through a business culture and practices that effectively create superior value for customers (Kohli and Jaworski 1990; Narver and Slater, 1990; Slater and Narver, 
2000, cf. Kumar et al. 2011). MO should lead to higher customer satisfaction, better customer loyalty and greater attractiveness to new customers, which in turn should be associated with better firm performance (Homburg and Pflesser, 2000). Hence, there is an implicit assumption that MO has a positive effect on firm performance. Literature reviews of Liao et al. (2011) and Raju et al. (2011) show that previous studies on the effect of MO on firm performance have, however, somewhat mixed results. The relationship can be moderated (for example competitive environment, intensity, product life cycle, and market growth) and mediated (for example innovation, learning, human resource or quality practices) by different factors. One reason for the mixed results might be that firm performance has not always been measured in a fully comparable manner. Also in studies on SMEs MO is shown to have a positive impact on firm performance, but performance is understood in various ways. For example, Dubihlela \& Dhurup (2015) and González-Benito et al. (2009) look at business performance, but Laukkanen et al. (2013) focus on brand and market performance. All in all, earlier research suggests strongly that MO has a positive effect on firm performance either directly or indirectly (e.g. Kumar et al., 2011; Baker and Sinkula 2009; González-Benito et al. 2014; Gaur, Vasudevan and Gaur, 2011; Pelham, 2000; Slater and Narver, 2000). Also meta-analyses largely confirm the positive effect of MO on firm performance (Cano et al. 2004; Kirca et al. 2005). In sum, therefore, we expect the relationship between MO and firm performance to be positive. Our first hypothesis is the following:

Hypothesis 1: Market orientation has a positive impact on firm performance

\section{Market orientation and PMS adoption}

MO has consequences for organizations. Kirca et al. (2005; see also Morgan et al. 2002) categorize these consequences into performance, customer, innovation and employee consequences, which in turn can be associated with the four different perspectives of the balanced scorecard (Kaplan and Norton 2005). There is both qualitative (Lamberti and Noci 2010; Martin, Martin and Minnillo 2009) and quantitative (Mintz and Currim 2013) empirical evidence that MO affects the measures used in PMS. A field study by Lamberti and Noci (2010) shows that firms with long-term relationships with customers and a strong attitude towards cooperation use several multidimensional measures. Another qualitative study by Martin et al. (2009) finds that MO leaders establish PMS to initiate and reward MO behavior among employees. A survey study by Perera et al. (1997) shows that customer-focus increases the use of non-financial measures, and Mintz and Currim (2013) find that firms with a greater MO use more marketing measures but not financial measures. In sum, existing studies shows 
that MO affects both PMS design and utilization and, although conclusions must be cautious because of differences in research designs, MO seems to increase PMS adoption.

The linkage between MO and PMS adoption can also be considered on a general level. Franco-Santos et al. (2012) propose that PMS can improve the strategic focus of the employees (see also Kohli \& Jaworski 1990), and Lamberti and Noci (2010) suggest that PMS can be used for marketing strategy communication, implementation, validation and learning. MO is associated with a focus on continuous creation of superior value for customers (Narver et al. 1998), which should naturally incline high MO firms to gather, produce and utilize information that can help them to identify the critical improvement areas in relation to their customers. Furthermore, if a good measure is relevant, objective, predictive, quality assured, reliable, sensitive, simple, and transparent (Stewart, 2009), it seems likely that more than one measure is needed to fulfill all the needs of a high MO firm. Overall, PMS emphasize the consideration of also the resources and inputs required to fulfill the needs of customers (e.g. Stewart 2009, see also Franco-Santos et al. 2012). While Slater and Narver (1994) argue that MO on the whole is cost-effective, even high MO firms need to control profitability and financial performance so that the costs of customer orientation do not exceed the revenues. Hence, although many studies focus on marketing performance measures ${ }^{1}$ (e.g. Lamberti and Noci 2010; Ambler et al. 2004; Homburg et al. 2012), we argue that adopting a general PMS is preferable over using only marketing performance measures.

To summarize, we argue that high MO firms are more likely to exhibit also a high degree of PMS adoption, i.e. to use multiple measures from different perspectives. Thus, our second hypothesis is:

Hypothesis 2: Market orientation has a positive impact on the PMS adoption

\section{Firm size and PMS adoption}

In addition to MO, other contextual factors affect PMS adoption and design in the firms (see Chenhall 2003; Ferreira and Otley 2009; Morgan et al. 2002). Earlier studies predict that larger firms have more formalized and sophisticated PMS (Chenhall 2003, see also Hoque and James 2000). This linkage is found also in a field study by Lamberti and Noci (2010) where larger firms have more structured marketing PMS. However, as the connection between size and PMS has been examined in context of large firms rather than SMEs (see ibid.), it deserves further attention. Mintz and Currim

\footnotetext{
${ }^{1}$ It should also be noted that marketing performance measures commonly include also measures employed in measuring firm performance, e.g. turnover; the distinction between PMS and its subset marketing PMS is not clear-cut.
} 
(2013), whose sample includes firms of all sizes, were unable to confirm that use of metrics increases with firm size.

However, at least three reasons can be proposed why increasing firm size has a positive impact on PMS adoption. First, larger firms have greater resources to implement sophisticated PMS. Second, decision-making processes such as planning and controlling are more challenging and complex in larger firms because they have a higher number of customers, products, market areas and employees than smaller firms. Third, direct interaction with all employees is not possible in larger firms and challenges in control arise (Davila 2005), leading to heavy reliance on PMS. Thus, our next hypothesis is the following:

Hypothesis 3: Increase in firm size has a positive impact on PMS adoption (the larger the firm, the greater PMS adoption)

\section{$\underline{\text { PMS adoption and firm performance }}$}

PMS, if it produces a variety of information, can be used for different purposes: controlling, planning, learning and strategic evaluation purposes (Morgan et al. 2002; Simons 1990). According to the literature review of Franco-Santos et al. (2012, see also Chenhall 2005; Garengo et al. 2005; Morgan et al. 2002; Nudurupati et al. 2011), PMS have impacts on people’s behavior, organizational capabilities and performance (organizational, team, managerial, inter-firm). This study focuses on firm level performance. PMS have been found to improve firm performance in three different ways: a better translation of strategy into operations, greater support for making strategizing continuous and improved alignment of various processes and organizational competencies (de Geuser et al. 2009, see also Chenhall 2005).

According to previous research results, having a number of different financial and non-financial performance measures benefits firm performance understood as e.g. one-year stock returns (Ittner et al. 2003) and return on assets and market returns (Said et al. 2003, see also Davis and Albrigth 2004; Hoque and James 2000). Also van der Stede et al. (2006) finds that firms have better performance if their PMS includes both subjective and objective non-financial measures, and Grafton et al. (2010) finds that PMS diversity helps exploit and identify the strategic capabilities that have a positive association with firm performance. The connection between PMS and performance may be influenced by features of strategic decision-making (Bisbe and Malaqueñô 2012).

Overall, PMS can be considered a critical and valuable resource for a firm, a resource which can be used for improving decision-making and thus gaining competitive advantage and improving firm 
performance (Franco-Santos ${ }^{2}$ et al. 2012; see also Barney et al. 2001). We expect that PMS adoption helps managers to understand occurring developments, trends, and events from different perspectives, and that this kind of understanding enables them to respond appropriately, which in turn improves firm performance. Such benefits should be available for SMEs also (Ates et al. 2013; Taticchi et al. 2010). Therefore, our next hypothesis is as follows:

Hypothesis 4: PMS adoption has a positive impact on firm performance

\section{Research design and method}

\section{Sampling frame and respondents}

The data for this study comes from SMEs that were also classified as growth firms in the three years' period 2002 - 2004 in the region of South Ostrobothnia in Finland. The definition of SME was taken from the European Union (EU recommendation 2003/361): “The category of micro, small and medium-sized enterprises is made up of enterprises which employ fewer than 250 persons and which have an annual turnover not exceeding EUR 50 million, and/or an annual balance sheet total not exceeding EUR 43 billion.

We used a mail survey to collect empirical data for the study. A questionnaire (Appendix 1) was sent in spring 2013 by mail to 262 SME firms. One reminder email was sent to all firms before the expiration of response time. Altogether 123 responses were received for the present study. One of the firms was too large to be categorized as SME, so it was not included in the analysis. The final data included 122 responses and the response rate was $47 \%$.

Among the sampled firms, $43 \%$ had one to five employees, $21 \%$ had six to ten employees, $16 \%$ had eleven to twenty employees, $14 \%$ had twenty to fifty employees and $6 \%$ had over fifty employees. The largest firm had 163 employees. The industries of the firms were: $32 \%$ services, $31 \%$ manufacturing, $28 \%$ retail trade, and $9 \%$ construction. $61 \%$ of the firms were operating only in domestic market. Among the sampled firms, 20 \% had annual sales of less than 200000 euros, $34 \%$ had sales of 200000 - 1 million euros, $31 \%$ were between 1 and 5 million euros, $9 \%$ had sales of 5 - 10 million euros and $6 \%$ had annual sales between 10 and 53 million euros.

\footnotetext{
${ }^{2}$ Franco-Santos et al. (2012) explains the different theories (such as agency, contingency, RBV, cognitive and information-processing, goal setting and procedural justice theories) which have been used for explaining the PMS design and use.
} 


\section{Measurement constructs}

\section{Market orientation}

Market orientation was measured using MARKOR-scale from Kohli et al. (1993). The original scale was shortened to 12 items as Homburg and Pflesser (2000) suggest when there are several concepts in addition to market orientation in the research setting. The MARKOR-scale has been extensively used in previous research related to market orientation and SMEs (e.g. Chao and Spillan 2010; Demirbag et al. 2006, Kara et al. 2005). Market orientation was measured with 12 items using seven point Likert scale (strongly disagree - strongly agree). Cronbach's alpha is .86 for market orientation. Thus, the instrument is reliable for measuring market orientation.

\section{Firm performance}

We measured firm performance by Chapman and Kihn (2009 see also Hyvönen, 2007) 10 item survey instrument. Their instrument is originally developed by Govindarajan and Fisher (1990) and Chenhall and Langfield-Smith (1998). We modified the instrument of Chapman and Kihn (2009) and added the solvency item because it is one key aspect of financial performance and subsequently our instrument includes 11 items. Following Artz et al. (2012), respondents were asked to rate their firm performance relative to competitors during the past three years. Seven-point Likert scale was used ranging from 1 (unsatisfactory) to 7 (excellent). The Cronbach's alpha was .88. Thus, the instrument is reliable for measuring firm performance.

\section{Performance measurement systems adoption}

We used ten items to measure the adoption of performance measurement systems. We asked respondents to rate the use of information in different perspectives (such as financial, customer, employee, suppliers, processes, quality) when they are evaluating the firm performance. Our sevenpoint Likert-scale ranged from 1 (not used at all) to 7 (used extensively). We applied Ittner et al. (2003) instrument to measure PMS adoption. The Cronbach’s alpha was .90. Thus, the instrument is reliable for measuring PMS adoption.

\section{Firm Size}

We used number of employees to measure the size of the company, following earlier MCS and PMS studies (for example Davila 2005; Hoque and James, 2000; Van der Stede et al. 2006). Due to the non-normality of size, we followed earlier studies and used natural logarithm (ln) of the firm size in the analysis (Davila 2005 see also Hoque and James 2000). 


\section{Data analysis method}

Initial data analysis was conducted using SPSS 22.0. First factor analysis was used to assess unidimensionality of scales. Second path analysis was used to understand comparative strengths of direct and indirect relationships among a set of studied variables. Path analysis is a statistical technique and a subset of Structural Equation Modeling (SEM) used to examine causal relationships between two or more variables ${ }^{3}$. We used AMOS 22 for conducting path analysis. We tested only the hypothesized pathways based on the theoretical predictions. The normality of scales was tested using Kolmogorov-Smirnov and Shapiro-Wilk -tests, which showed that all the variables in our model were normally distributed. Podsakoff et al. (2003) reminds that common method biases can be a potential problem when data for both the predictor and criterion variable are obtained from the same person in the same measurement context using the same item context and similar item characteristics. They recommend that researchers follow good measurement practice and also implement additional procedural and statistical remedies to control for the method biases. One way of doing this is to use Harman's single factor test: all of the studied variables are loaded into an exploratory factor analysis and unrotated factor solution is examined. The basic assumption is that if a substantial amount of common method variance is present, either a single factor will emerge or one general factor will account for the majority of the covariance among the measures. We used Harman's single factor test to control for the method biases. All the items used to create the main variables, a total of 31 items, were factor analysed using principal axis factoring where the unrotated factor solution was examined, as recommended by Podsakoff et al. (2003). Kaiser's criterion for retention of factors was followed. The sample size seemed to be large enough for the factor analysis, at least based on the Kaiser-MeyerOlkin measure of sampling adequacy $(\mathrm{KMO}=0.83)$. Factor analytic results indicated the existence of several factors with eigenvalues greater than 1.0. The first factor accounted for 33 percent of the variance. Since several factors, as opposed to one single factor, were identified and since the first factor did not account for the majority of the variance, a substantial amount of common method variance does not appear to be present.

Different measures were used to evaluate path model fit. We used measures suggested by Byrne (2010); acceptable model fit was operationalized as $X^{2} /$ degrees of freedom ( $d f$ ) ratios (CMIN/DF) less than 3.0, Comparative Fit Index (CFI) values greater than .90, Normal Fit Index (NFI) values

\footnotetext{
${ }^{3}$ Alternatively, partial-least squares (PLS) technique could be used also in this study. We had two reasons to use SEM instead of PLS. First, we wanted to have goodness of fit measures for the model (Gefen et al. 2011; Fink et al. 2016). Second, SEM has been applied also in earlier studies where sample size has not been high (e.g. 88 usable responses in Baker and Sinkula 2009; 123 in Homburg et al. 2012; 159 in Fink et al. 2016). Finally, we are rather testing theoretically assumed relationships than identifying or predicting these relationships and thus SEM seems to be more suitable than PLS for the purposes of our study (Reinartz et al. 2009 see also Hair et al. 2011).
} 
greater than 0.95 and Root Mean Square Error of Approximation (RMSEA) values less than .08. To have confidence in the goodness of fit test, a sample size of 100 to 200 is recommended (Hoyle 1995). In general a model should contain 10 to 20 times as many observations as variables (Mitchell 1993). Our sample size was 122, so it was adequate for testing the goodness of fit. The model has five variables, so the recommendation of Mitchell (1993) is also followed. It should be noted, that we apply measured variable path analysis and test also the mediation. Baron and Kenny (1986) define that mediation is a hypothesized causal chain in which one variable affects a second variable that, in turn, affects a third variable. They also propose a four step approach in which several regression analyses are conducted. The use of AMOS gives us the possibility to conduct these regression analyses simultaneously and it also provides direct and indirect effects of the variables. After using AMOS, we further checked the mediation according to Baron and Kenny (1986).

\section{Results}

Kaiser-Meyer-Olkin measure (.83) showed that factor analysis is appropriate for this data. From the 11 items measuring firm performance, two factors were extracted. These accounted 63 percent of the variance of firm performance and they had eigenvalue greater than 1.0. We used Varimax rotation to determine the variables within each factor. Table 1 shows the communalities for each variable and the factor loadings for these factors after rotation.

\begin{tabular}{|llll|}
\hline Variable & Communality & Factor 1 & Factor 2 \\
\hline Return on investment &, 78 &, 86 & \\
Profit &, 76 &, 83 & \\
Cash flow from operations &, 75 &, 86 & \\
Solvency (equity ratio, gearing) &, 59 &, 77 & \\
Cost control &, 44 &, 62 & \\
Development of new products &, 49 & &, 66 \\
Sales volume &, 73 & &, 84 \\
Market share &, 66 & &, 80 \\
Market developments &, 73 & &, 85 \\
Personnel developments &, 54 & &, 69 \\
Political-public affairs &, 45 & &, 63 \\
\hline
\end{tabular}

Table 1. Factor analysis for the firm performance

Cronbach's alphas were calculated for each scale. Factor 1 was named as "financial performance" with Cronbach’s alpha .87. Factor 2 was named as “non-financial performance” with Cronbach’s 
alpha .86. Thus, these two factors have high reliability ratios. Descriptive statistics and correlation matrix are presented in Table 2.

\begin{tabular}{|c|c|c|c|c|c|}
\hline & 1 & 2 & 3 & 4 & 5 \\
\hline 1. FINANCIAL PERFORMANCE & 1 & & & & \\
\hline 2. NON-FINANCIAL PERFORMANCE &, $45^{* * *}$ & 1 & & & \\
\hline 3. FIRM SIZE & ,17 &, $26^{* *}$ & 1 & & \\
\hline 4. MARKET ORIENTATION &, $36^{* * *}$ &, $62^{* * *}$ &, 14 & 1 & \\
\hline 5. PMS ADOPTION &, $48^{* * *}$ &, $62^{* * *}$ & $28^{* *}$ &, $63^{* * *}$ & 1 \\
\hline Mean & 4,78 & 4,46 & 2,02 & 4,70 & 4,24 \\
\hline SD & 1,15 & 1,01 & 1,21 & 1,03 & 1,13 \\
\hline Range & $1,80-7,00$ & $1,67-6,83$ & ,00-5,09 & $1,25-6,83$ & $1,00-6,60$ \\
\hline
\end{tabular}

\section{Table 2. Correlation matrix and descriptive statistics for study variables}

Based on the factor analysis, we added separate paths for non-financial and financial performance from PMS adoption and from market orientation. The modified path model was tested. Although CMIN/DF (2.05), NFI (.96) and CFI (.98) values were acceptable, RMSEA fit measures indicated an inadequate fit (.93). We also discovered that market orientation had a direct effect on non-financial performance $(\beta=.40 p<0.001)$ but a non-significant effect on financial performance $(\beta=.13 p=0.237)$.

The Figure 2 presents the empirical model. Firm performance is divided into non-financial and financial performance as suggested by the results of factor analysis. The model has good fit measures $(\mathrm{CFI}=.98 ; \mathrm{NFI}=0.96 ; \mathrm{RMSEA}=.08 ; \mathrm{CMIN} / \mathrm{DF}=1.82)$. In addition, the squared multiple correlation of a variable is the proportion of its variance that is accounted for by its predictors (Arbuckle 2007). As can be seen from the Figure 2, the empirical model explains 51\% of the variance in the non-financial performance and $23 \%$ of the variance in the financial performance. $\mathrm{MO}$ and firm size explain $44 \%$ of the variance in PMS adoption.

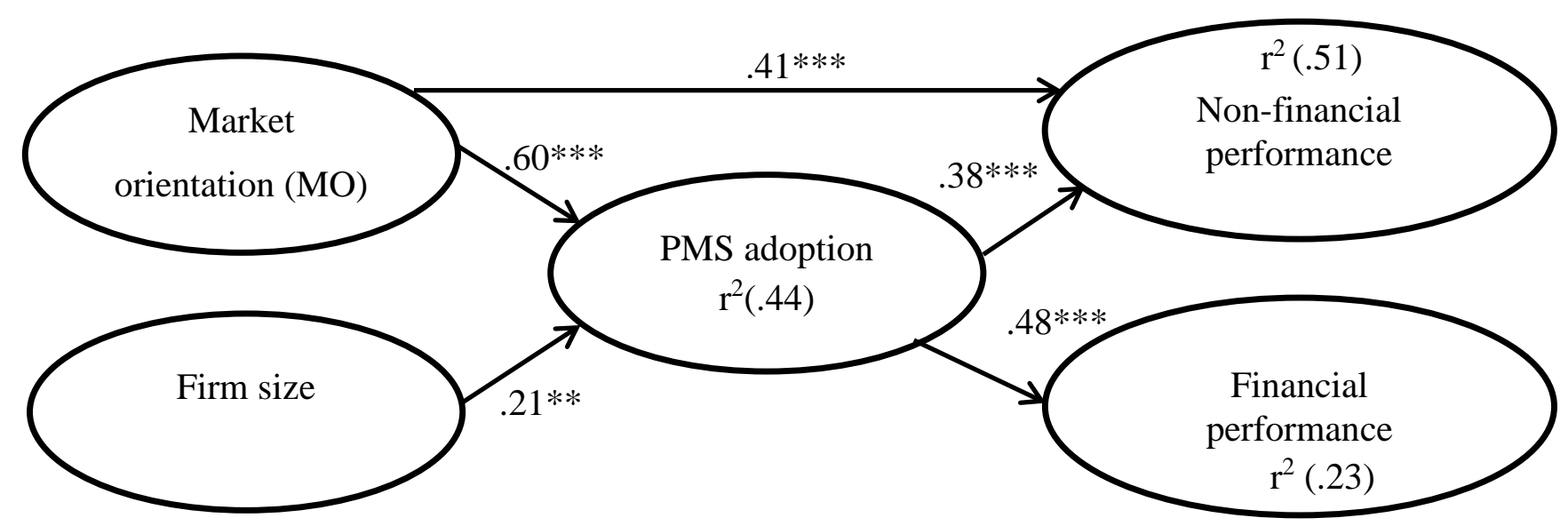


Notes: chi-square $=.73, \mathrm{df}=4, \mathrm{p}=.12, \mathrm{CMIN} / \mathrm{DF}=1.82, \mathrm{CFI}=.98, \mathrm{NFI}=.96, \mathrm{RMSEA}=.08$

$* \mathrm{p}<.05 .{ }^{* *} \mathrm{p}<.01 .{ }^{* * *} \mathrm{p}<.001$

\section{Figure 2. Final empirical model}

Table 3 shows the regression estimates and p-values for significance.

\begin{tabular}{|c|c|c|c|c|c|c|c|c|}
\hline Path from & & Path to & $\begin{array}{l}\text { Stand. } \\
\text { regr. } \\
\text { weight }\end{array}$ & Estimate & S.E. & C.R. & $\mathrm{P}$ & $\begin{array}{l}\text { Confirmation } \\
\text { of hypothesis }\end{array}$ \\
\hline $\begin{array}{l}\text { Market } \\
\text { orientation }\end{array}$ & $\rightarrow$ & $\begin{array}{l}\text { Non-financial } \\
\text { performance }\end{array}$ & ,41 & ,41 & ,09 & 4,75 & $* * *$ & $\begin{array}{l}\text { H1 partially } \\
\text { supported }\end{array}$ \\
\hline $\begin{array}{l}\text { Market } \\
\text { orientation }\end{array}$ & $\rightarrow$ & PMS adoption & ,60 & ,66 & ,08 & 8,27 & $* * *$ & H2 supported \\
\hline Firm size & $\rightarrow$ & PMS adoption & ,21 & ,19 & ,07 & 2,85 & $* *$ & H3 supported \\
\hline PMS Adoption & $\rightarrow$ & $\begin{array}{l}\text { Financial } \\
\text { performance }\end{array}$ & ,48 & ,49 & ,09 & 5,73 & $* * *$ & H4 supported \\
\hline PMS Adoption & $\rightarrow$ & $\begin{array}{l}\text { Non-financial } \\
\text { performance }\end{array}$ & ,38 & ,35 & ,08 & 4,43 & $* * *$ & H4 supported \\
\hline
\end{tabular}

Table 3. Estimates and Standardized Regression Weights of the Empirical Model

As can be seen from the Table 3, MO has a significant and positive impact on PMS adoption ( $\beta=.60$ $\mathrm{p}<0.001$ ) supporting hypothesis 2 . MO has a positive significant effect on non-financial performance $(\beta=.41 \mathrm{p}<0.001)$ but the effect on financial performance is mediated by PMS adoption. This means that hypothesis 1 is supported only partially from the non-financial perspective of firm performance. Firm size has a significant and positive impact on the PMS adoption $(\beta=.21 \mathrm{p}<0.01)$ supporting hypothesis 3. Finally, PMS adoption has a significant and positive impact both on financial ( $\beta=.48$ $\mathrm{p}<0.001)$ and non-financial performance $(\beta=.38 \mathrm{p}<0.001)$ supporting hypothesis 4 . Furthermore, $\mathrm{MO}$ has a direct and also an indirect effect on non-financial performance mediated by PMS adoption. PMS adoption also seems to mediate the effect of firm size on financial and non-financial performance in addition to MO. However, this mediation was further analyzed in the next step.

With path analysis, the relationships can be conceptualized as direct, indirect and total effects. The total effect of one variable on another is the sum of its direct and indirect effects. Total effect of market orientation on non-financial performance is .64, with an indirect effect via PMS adoption .23.

The indirect effect of MO on financial performance via PMS adoption is .29. Hypothesis 1 is therefore supported partially: MO and non-financial performance have a positive relationship but the effect on financial performance is mediated through PMS adoption. The indirect effect of firm size is .10 on 
financial performance. Firm size has a small indirect effect (.08) on non-financial performance via PMS adoption.

To further check for mediation, Baron and Kenny (1986) propose a simple four step approach in which several regression analyses are conducted and the significance of the coefficients is examined at each step. First a regression analysis is done where MO predicts financial performance. Second regression analysis tests a path from MO to PMS adoption. Third regression analysis tests the significance of path from PMS adoption to financial performance. The purpose of steps 1-3 is to establish that zero-order relationships among the variables exist. If one or more of these relationships are nonsignificant, mediation is not possible or likely.

In the first step, we found significant relationship between $\mathrm{MO}$ and financial performance $(\beta=.36$, $\mathrm{p}<0.001)$. In second step we found a significant effect of MO on PMS adoption $(\beta=.63, p<0.001)$. In the third step the relationship between PMS adoption and financial performance was found also to be significant $(\beta=.48, \mathrm{p}<0.001)$. After taking steps $1-3$ we proceeded to step 4 as Baron and Kenny (1986) recommend.

In the Step 4 model, some form of mediation is supported if the effect of PMS adoption on financial performance remains significant after controlling for MO. If the effect of MO is no longer significant when PMS adoption is controlled, the finding supports full mediation. If MO is still significant (i.e., both PMS adoption and MO significantly predict performance), the finding supports partial mediation.

Table 4 presents the results from Step 4. As can be seen from the table, MO is no longer significant in the model when PMS adoption is added. PMS adoption has a significant effect on financial performance. This suggests that PMS adoption fully mediates the effect of MO on financial performance.

\begin{tabular}{|ll|}
\hline Independent variables \\
\hline PMS adoption & $0.40^{* * *}$ \\
Market orientation & 0.13 \\
Model fit statistics & \\
Adjusted $\mathrm{R}^{2}$ & 0.23 \\
F-statistics & $16.167^{* * *}$ \\
\hline$+\mathrm{p}<.10 .^{*} \mathrm{p}<.05 .{ }^{* *} \mathrm{p}<.01 .{ }^{* * *} \mathrm{p}<.001$ \\
\hline
\end{tabular}

Table 4. Results of the linear regression analysis testing mediation.

The same procedure was done for testing the mediation of PMS adoption on the relationship with firm size and financial performance. The first step showed that the relationship between firm size and 
financial performance was not significant, therefore no more models were run. This suggests that the mediation is not possible or likely. Firm size has a direct effect on PMS adoption but PMS adoption does not mediate the effect of firm size on financial performance. However, firm size had a direct and significant effect in the first step on non-financial performance $(\beta=.26, p<0.01)$. Also other relationships were significant in the steps 2-3 (Firm size on PMS adoption: $\beta=.28, p<0.01$; PMS adoption on non-financial performance: $\beta=.62, \mathrm{p}<0.001$ ). In the fourth step the model showed that the effect of firm size was insignificant when PMS adoption was added in the model. This suggests that PMS adoption fully mediates the effect of firm size on non-financial performance of the firm.

\section{Discussion}

This study sought to clarify the association between MO and PMS adoption, and their relationship with firm performance, in the context of SMEs. We contribute to earlier studies in several ways. First, we apply quantitative empirical data (cf. Lamberti and Noci 2010). Second, we focus on general (not only marketing) PMS (cf. Homburg et al. 2012; O’Sullivan and Abela 2007). Third, we measure overall firm performance and not only customer or marketing performance (cf. Hyvönen 2007; Mintz and Currim 2013). Finally, the study focuses on SMEs, a context in which PMS adoption has been little studied, as PMS are commonly considered more valuable for larger firms (Ates et al. 2013; Chenhall 2003; Taticchi et al. 2010 see also Homburg et al. 2012).

The results show clearly that SMEs with high MO are more likely to adopt PMS than those with low MO. In other words, it appears that MO increases the importance of having a variety of performance metrics. In this, our results differ from those of Mintz and Currim (2013, see also O’Sullivan and Abela 2007) who found that greater MO increased managers' use of marketing measures but not financial measures. According to our analysis, MO increases also the use of financial and other types of information (e.g. innovation, employees, processes and quality). This suggests that PMS adoption is an important alignment tool for SMEs with high MO; having a wide range of information available for instance from customers, employees, internal processes, stakeholders and financial success enable a more comprehensive view and thus better implementation of MO as well.

This study also sheds more light on the relationships between MO, PMS adoption and firm performance. According to Homburg et al. (2012), the relationship between PMS and firm performance is mediated by marketing alignment and market knowledge. In our study we have extended the analysis in the opposite direction, suggesting and confirming that PMS adoption mediates the relationship between MO and firm performance (cf. Hyvönen 2007). Thus, our results 
indicate that PMS play an important role in the relationship between MO and firm performance also in SMEs. In relation to Hyvönen (2007), our results indicate that PMS adoption has a mediating rather than moderating effect on the relationship. Furthermore, we measured overall firm performance (including financial and non-financial perspectives) of the companies rather than relying on customer performance only which is a contribution to these earlier studies.

A study by Chao and Spillan (2010) argues that in SMEs responsiveness is the key element of MO as far as impact on performance is concerned. One possible explanation for the mediation of MO impact on performance by PMS adoption found in our study could be that PMS adoption indicates management commitment to maintaining a balanced view on performance, and this in turn helps maintain response capability. In other words, SMEs that make an effort to measure performance systematically, using widespread measures, are also better able to implement coherent responses to market needs.

We were also able lend some support, in the context of SMEs, to earlier positive results on the relationship between $\mathrm{MO}$ and firm performance; although in our data the impact of MO on financial performance was indirect, there was a direct and positive effect on non-financial performance. The impact of PMS adoption on firm performance was unequivocally supported by our study. We feel that, as there are so far few studies on the effects of PMS adoption in SME contexts, this is an important result. PMS are shown to be valuable also in SMEs, although SMEs have characteristics which may limit PMS adoption in practice (e.g. Ates at al. 2013; Garengo et al. 2005). One reason for the usefulness of PMS adoption in SME context might be that PMS can be utilized in several ways, e.g. controlling, planning, learning and strategic evaluation (e.g. Morgan et al. 2002), all of which are highlighted also in maintaining high MO. According to Martin et al. (2009), MO needs clear and systematic goals and our result indicate that PMS adoption enables systematic establishment of measures and control for achieving of targets. Systematic management of information - PMS adoption in the case of our study - has potentially a strong impact on both non-financial and financial performance in high MO SMEs.

\section{Practical implications}

As a practical implication, our results show that the importance of PMS in realizing benefits from MO should not be underestimated. MO alone will not deliver the same firm performance impact. In other words, PMS adoption considerably enhances the effect of MO on firm performance. PMS enable the setting of targets and measuring of achievements not immediately associated with marketing, using e.g. financial, process and employees' perspectives. This is an important 
contribution to the more limited marketing performance perspective. In particular, the positive effect of MO on financial performance is increased by adopting PMS. Secondly, MO focus has a positive and direct impact on non-financial performance. This means that if a firm emphasizes improvements in non-financial performance only, MO focus alone may suffice and PMS adoption is not required.

Finally, as the role of marketing function tends to be relatively small in SMEs (Walsh \& Lipinski, 2009), this positive mediating association of PMS adoption between MO and firm performance should encourage marketing managers to promote adoption of PMS within their firms. Increase in systematic measurement is likely to improve both marketing's position within the firm and firm performance. Thus calls for different measures from different perspectives, including customer measures, should not be viewed as a threat by marketing managers. Even firms that consider themselves culturally customer-responsive should make an effort to develop hard measures for their activities.

\section{Limitations and further research}

This study has also some obvious limitations. First, the sample size is quite small and drawn from a single economic and cultural setting. Second, our scope is limited to only a few of the many potentially related concepts that have not been extensively studied in SME contexts. According to Chenhall (2003), factors relating for instance to environment, technology and culture have been found to affect PMS adoption. Thirdly, this study focused on the degree of PMS adoption, i.e. the variety of measures used to analyze firm performance; hence, other management control systems were not addressed. In addition to PMS adoption, MO may influence also planning and reward systems (Malmi and Brown 2008; Jaworski and Kohli 1993). Also, qualitative research methods might be appropriate for investigating how PMS are constructed, what measures are used as key measures and how they are applied in different decision-making situations in high MO firms (Länsiluoto et al. 2013). These limitations should be addressed in future studies. Finally, we suggest that studies further examining the linkages between the different elements of MO (see Chao and Spillan 2010), PMS and firm performance should be undertaken in SME and small business contexts specifically.

\section{Conclusions}

In this paper we contribute the earlier literature of MO, PMS adoption and firm performance in the context of SMEs. Previous research has shown that market orientation (MO) and firm performance are connected, and that performance measurement systems (PMS) adoption and firm performance are connected, but the mutual interactions of the three have not been examined in SME contexts. 
According to our results, MO has positive relationships with PMS adoption and non-financial performance. However, $\mathrm{MO}$ and financial performance have an indirect relationship when mediated by PMS adoption. Thus, both MO and PMS adoption are determinants of firm performance in SMEs but they have a different effect. Adoption of PMS enhances the effect of MO on firm financial performance. The study concludes that MO firms benefit both from non-financial and financial perspectives if they utilize measures from several different perspectives such as community, customers, environment, financial performance, innovation and process perspectives. Therefore, the study contributes contingency theory (see Chenhall 2003) by suggesting PMS to be beneficial also for SMEs with high MO.

\section{References}

Ambler, T., Kokkinaki, F. and Puntoni, S. (2004). ”Assessing Marketing Performance: Reasons for Metrics Selection.” Journal of Marketing Management 20 (3/4), 475-498.

Arbuckle, J. (2007). Amos 18 User’s Guide. Chicago. Amos Development Corporation.

Artz M., C. Homburg, and T. Rajab (2012). "Performance-measurement system design and functional strategic decision influence: The role of performance-measure properties," Accounting, Organizations and Society 37(7), 445-460.

Ates, A., P. Garengo, P. Cocca, and U. Bititci (2013). “The development of SME managerial practice for effective performance management," Journal of Small Business and Enterprise Development 20(1), 28-54.

Baker, W. E., and J. M. Sinkula (2009). "The Complementary Effects of Market Orientation and Entrepreneurial Orientation on Profitability in Small Businesses," Journal of Small Business Management 47(4), 443-464.

Barney, J., M. Wright, and D. Ketchen (2001). "The resource-based view of the firm: Ten years after 1991,” Journal of Management 27(6), 625-641.

Baron, R. and D. Kenny (1986). “The moderator-mediator variable distinction in social psychological research: Conceptual, strategic, and statistical considerations,” Journal of Personality and Social Psychology 51, 1173-1182.

Bisbe, J., and R. Malagueño (2012). "Using strategic performance measurement systems for strategy formulation: Does it work in dynamic environments?,” Management Accounting Research 23(4), 296-311.

Byrne, B. (2010). Structural Equation Modeling with AMOS. Basic Concepts, Applications, and Programming. 2nd edition. New York: Routledge. 
Cano, C.R., F. A. Carrillat, and F. Jaramillo (2004). "A meta-analysis of the relationship between market orientation and business performance: evidence from five continents,” International Journal of Research in Marketing 21(2), 179-200.

Chao, M. and J. Spillan (2010). “The journey from market orientation to firm performance. A comparative study of US and Taiwanese SMEs,” Management Research Review 33(5), 472-483.

Chapman, C., and L.-A. Kihn (2009). "Information system integration, enabling control and performance,” Accounting, Organizations and Society 34(2), 151-169.

Chenhall, R. H. (2005). “Integrative strategic performance measurement systems, strategic alignment of manufacturing, learning and strategic outcomes: an exploratory study," Accounting, Organizations and Society 30(5), 395-422.

Chenhall, R. (2003). "Management control systems design within its organizational context: findings from contingency-based research and directions for the future," Accounting Organizations and Society 28(2-3), 127-168.

Chenhall, R. H., and K. Langfield-Smith (1998). "The relationship between strategic priorities, management techniques and management accounting: an empirical investigation using system approach,” Accounting, Organizations and Society 23(3), 243-264.

Davila, T. (2005). “An exploratory study on the emergence of management control systems: formalizing human resources in small growing firms," Accounting, Organizations and Society 30(3), 223-248.

Davis, S., and T. Albright (2004). "An investigation of the effect of Balanced Scorecard implementation on financial performance,” Management Accounting Research 15(2), 135-153.

De Geuser F., S. Mooraj, and D. Oyon (2009). "Does the balanced scorecard add value? Empirical evidence on its effect on performance,” European Accounting Review 18(1), 93-122.

Demirbag, M., S.C. L. Koh, E. Tatoglu and S. Zaim (2006). “TQM and market orientation’s impact on SMEs’ performance,” Industrial Management \& Data Systems 106(8), 1206-1228.

Dubihlela, J. and M. R. Dhurup (2015). “Determinants of, and barriers to, market orientation and the relationship with business performance among SMEs,” The Journal of Applied Business Research 31(5), 1667-1678.

European Union. EU recommendation 2003/361.

Ferreira, A., and D. Otley (2009). "The design and use of performance management systems: An extended framework for analysis,” Management Accounting Research 20(4), 263-282. 
Fink L., Yogev N., and A. Even (2016). "Business Intelligence and Organizational Learning: An Empirical Investigation of Value Creation Processes," Information and Management, http://dx.doi.org/10.1016/j.im.2016.03.009

Franco-Santos, M., L. Lucianetti, and M. Bourne (2012). “Contemporary performance measurement systems: A review of their consequences and a framework for research,” Management Accounting Research 23(2), 79-119.

Garengo, P,, S. Biazzo, and U.S. Bititci (2005). "Performance measurement systems in SMEs: A review for a research agenda,” International Journal of Management Reviews 7(1), 25-47.

Gaur, S., H. Vasudevan, and A. Gaur (2011). "Market orientation and manufacturing performance of Indian SMEs. Moderating role of firm resources and environmental factors,“ European Journal of Marketing 45(7/8), 1172-1193.

Gefen, D., E.E. Rigdon, and D. Straub (2011). “An update and extension to SEM guidelines for administrative and social science research,” MIS Quarterly 35(2), pp. iii-xiv.

Govindarajan, V., and J. Fisher (1990). "Strategy, control systems, and resource sharing: effects on business unit performance,” Academy of Management Journal 33(2), 259-285.

González-Benito, O., J. González-Benito, and P. A. Muñoz-Gallego (2014). "On the Consequences of Market Orientation across Varied Environmental Dynamism and Competitive Intensity Levels," Journal of Small Business Management 52(1), 1-21.

González-Benito, O., J. González-Benito, and P. A. Muñoz-Gallego (2009). "Role of entrepreneurship and market orientation in firms' success," European Journal of Marketing 43(3/4), 500-522.

Grafton, J., A. M. Lillis, and S. K. Widener (2010). "The role of performance measurement and evaluation in building organizational capabilities and performance," Accounting, Organizations and Society 35(7), 689-706.

Hair, J.F., C. M. Ringle, and M. Sarstedt (2011). "PLS-SEM: Indeed a Silver Bullet," Journal of Marketing Theory and Practice 19(2), 139-152.

Homburg, C., M. Artz, and J. Wieseke (2012). ”Marketing Performance Measurement Systems: Does Comprehensiveness Really Improve Performance?,” Journal of Marketing 76(3), 56-77.

Homburg, C., and C. Pflesser (2000). "A Multiple-Layer Model of Marketing-Oriented Organizational Culture: Measurement Issues and Performance Outcomes,” Journal of Marketing Research 37(4), 449-462.

Hoque, Z., and W. James (2000). ”Linking balanced scorecard measures to size and market factors: impact on organizational performance.” Journal of Management Accounting Research 12, 1-17.

Hoyle, R.H. (ed.) (1995). Structural Equation Modeling. SAGE Publications, Inc. Thousand Oaks, CA. 
Hult, T., D. Ketchen Jr. and S. Slater (2005). "Market Orientation and Performance: An Integration of Disparate Approaches.” Strategic Management Journal 26(12), 1173-1181.

Hyvönen, J. (2007). "Strategy, performance measurement techniques and information technology of the firm and their links to organizational performance,” Management Accounting Research 18(3), 343-366.

Ittner, C., D. Larcker, and T. Randall (2003). ”Performance implications of strategic performance measurement in financial services firms," Accounting, Organizations and Society 28(7-8), 715-741.

Jaworski, B. J., and A. K. Kohli (1993). ”Market Orientation: Antecedents and Consequences,” Journal of Marketing 57(3), 53-70.

Kaplan, R.S., and D. P. Norton (2005). ”The balanced scorecard: Measures that drive performance, Harvard Business Review,” 83(7/8), 172-180.

Kara, A., J. Spillan and O. DeShields (2005). “The Effect of a Market Orientation on Business Performance: A Study of Small-Sized Service Retailers Using MARKOR Scale.” Journal of Small Business Management 43(2), 105-118.

Kirca, A. H., S. Jayachandran, and W. O. Bearden (2005). "Market Orientation: A Meta-Analytic Review and Assessment of Its Antecedents and Impact on Performance," Journal of Marketing 69(2), 24-41.

Kohli, A. K., and B. J. Jaworski (1990). "Market Orientation: The Construct, Research Propositions, and Managerial Implications,” Journal of Marketing 54(2), 1-18.

Kohli, A. K., B. J. Jaworski, and A. Kumar (1993). ”MARKOR: A Measure of Market Orientation,” Journal of Marketing Research 30(4), 467-477.

Kumar, V., Jones, E., Venkatesan, R. \& Leone, R. (2011). ”Is market orientation a source of sustainable competitive advantage or simply the cost of competing?," Journal of marketing 75(1), 16-30.

Lamberti, L., and G. Noci (2010). "Marketing strategy and marketing performance measurement system: Exploring the relationship,” European Management Journal 28(2), 139-152.

Laukkanen, T., G. Nagy, S. Hirvonen, H. Reijonen and M. Pasanen (2013). ”The effect of strategic orientations on business performance in SMEs. A multigroup analysis comparing Hungary and Finland,” International Marketing Review 30(6), 510-535.

Liao, S.-H., W.-J. Chang, C.-C Wu, and J. M. Katrichis (2011). “A survey of market orientation research (1995-2008),” Industrial Marketing Management 40(2), 301-310.

Länsiluoto, A., M. Järvenpää and K. Krumwiede (2013). "Conflicting interests but filtered key targets: Stakeholder and resource-dependency analyses at a University of Applied Sciences," Management Accounting Research 24(3), 228-245. 
Malmi, T., and D. A. Brown (2008). "Management control systems as a package - Opportunities, challenges and research directions,” Management Accounting Research 19(4), 287-300.

Martin, J. H., B. A. Martin and P. R. Minnillo (2009). "Implementing a Market Orientation in Small Manufacturing Firms: From Cognitive Model to Action,” Journal of Small Business Management 47(1), 92-115.

Mintz, O., and I. S. Currim (2013). "What Drives Managerial Use of Marketing and Financial Metrics and Does Metric Use Affect Performance of Marketing-Mix Activities?," Journal of Marketing 77(2), 17-40.

Mitchell, R.J. (1993). Path analysis: pollination. In: Design and Analysis of Ecological Experiments (Scheiner, S.M. and J. Gurevitch, Eds.). Chapman and Hall, Inc. New York, NY, 211-231.

Morgan, N. A., B. H. Clark, and R. Gooner (2002). "Marketing productivity, marketing audits, and systems for marketing performance assessment: Integrating multiple perspectives,” Journal of Business Research 55(5), 363-375.

Narver, J. C., and S. F. Slatar (1990). "The effect of a market orientation on business profitability," Journal of Marketing 54(4), 20-35.

Nudurupati, S. S., U. S. Bititci, V. Kumar, and F.T.S. Chan (2011). "State of the art literature review on performance measurement,” Computers \& Industrial Engineering 60(2), 279-290.

O'Sullivan, D. and A.V. Abela (2007). "Marketing Performance Measurement Ability and Firm Performance,” Journal of Marketing 71(2), 79-93.

Pelham, A. (2000). "Market orientation and other potential influences on performance in small and medium-sized manufacturing firms,” Journal of Small Business Management 38(1), 48-67.

Perera, S., G. Harrison, and M. Poole (1997). "Customer-focused manufacturing strategy and the use of operations-based non-financial performance measures: A research note," Accounting, Organizations and Society 22(6), 557-572.

Podsakoff, P. M., S.B. MacKenzie, J-Y. Lee and N.P. Podsakoff (2003). "Common Method Biases in Behavioral Research: A Critical Review of the Literature and Recommended Remedies,” Journal of Applied Psychology 88(5), 879-903.

Raju, P. S., S. C. Lonial, and M. D. Crum (2011). "Market orientation in the context of SMEs: A conceptual framework,” Journal of Business Research 64(12), 1320-1326.

Reinartz, W., M. Haenlein, and J. Henseler J. (2009). “An empirical comparison of the efficacy of covariance-based and variance-based SEM,” International Journal of Research in Marketing 26(4), 332-344.

Said, A. A., H. R. HassabElnaby, and B. Wier (2003). "An Empirical Investigation of the Performance Consequences of Nonfinancial Measures," Journal of Management Accounting Research 15, 93-223. 
Simons, R. (1990). “The role of management control systems in creating competitive advantage: New perspectives,” Accounting, Organizations and Society 15(1-2), 127-143.

Slater, S. F., and J. C. Narver (1994). "Does competitive environment moderate the market orientation - performance relationship?,” Journal of Marketing 58(1), 46-55.

Slater, S. F., and J. C. Narver (2000). "The Positive Effect of a Market Orientation on Business Profitability: A Balanced Replication,” Journal of Business Research 48(1), 69-73.

Stewart, D. W. (2009). "Marketing accountability: Linking marketing actions to financial results," Journal of Business Research 62(6), 636-643.

Taticchi, P., F. Tonelli, and L. Cagnazzo (2010). "Performance measurement and management: a literature review and a research agenda,” Measuring Business Excellence 14(1), 4-18.

Tsamenyi, M., S. Sahadev, Z. Shi Qiao (2011). “The relationship between business strategy, management control systems and performance: Evidence from China,” Advances in Accounting 27(1), 193-203.

Walsh, M. F., and J. Lipinski (2009). “The role of the marketing function in small and medium sized enterprises,” Journal of Small business and Enterprise Development 16(4), 569-585.

Van der Stede, W. A., C. W. Chow, and T. W. Lin (2006). "Strategy, Choice of Performance Measures, and Performance,” Behavioral Research in Accounting 18(1), 185-205.

\section{Appendix. The survey instrument}

Market orientation [based on Homburg and Pflesser (2000) adopted from MARKOR-scale (Kohli et al. 1993)]

Scale [1 = totally disagree, 7 = totally agree $]$

1. In this business unit, we meet with customers at least once a year to find out what products or services they will need in the future.

2. We are slow to detect changes in our customers' product preferences. (reverse coded)

3. We poll end users at least once a year to assess the quality of our products and services.

4. We are slow to detect fundamental shifts in our industry (e.g., competition, technology, regulation). (reverse coded)

5. We have interdepartmental meetings at least once a quarter to discuss market trends and developments.

6. Marketing personnel in our business unit spend time discussing customers' future needs with other functional departments.

7. When something important happens to a major customer or market, the whole business unit knows about it within a short period.

8. Data on customer satisfaction are disseminated at all levels in this business unit on a regular basis.

9. We periodically review our product development efforts to ensure that they are in line with what customer want. 
10. Several departments get together periodically to plan a response to changes taking place in our business environment.

11. The activities of the different departments in this business unit are well coordinated.

12. When we find that customers would like us to modify a product or service, the departments involved make concerted efforts to do so.

Performance measurement system adoption [based on Ittner et al. 2003]

How would you rate the use of information in the following perspectives when you are evaluating the firm performance?

Scale [1 = not used at all, 7 = used extensively $]$

Short-term financial performance (e.g. annual earnings, return on assets, gearing, liquidity)

Customers (e.g. market share, customer satisfaction, sales qrowth)

Employees (e.g. employee satisfaction, turnover, employee costs)

Supplier relations (e.g. on-time delivery, input into product/service design)

Internal operational performance (e.g. productivity, safety, cycle time)

Product and service quality (e.g. defect rates, faulty products)

Alliances with other organizations (e.g. joint marketing, product design, production)

Environmental performance (e.g. environmental compliance or certification)

Product and service innovation (e.g. new product or service development success, development cycle time)

Community (e.g. public image)

Firm performance [based on Chapman and Kihn (2009) and Govindarajan and Fisher 1990]

How would you rate your performance relative to competitors during the past three years?

Scale [1 = unsatisfactory, 7 = excellent $]$

Return on investment

Profit

Cash flow from operations

Solvency (equity ratio, gearing)

Cost control

Development of new products

Sales volume

Market share

Market developments

Personnel developments

Political-public affairs 